\title{
Bromodeoxyuridine (BrdU) marker for proliferating cells in living tis- sues: Detection in adult avian brain
}

\author{
Yatinesh Kumari ${ }^{1,2 *}$ \\ ${ }^{1}$ Jeffrey Cheah School of Medicine and Health Sciences, Monash University Malaysia, Bandar Sunway, Subang Jaya, Selan- \\ gor, 47500, Malaysia \\ ${ }^{2}$ Department of Zoology, University of Lucknow, Lucknow 226 007, India
}

\begin{abstract}
Knowing how to perform cell proliferation assays is an undeniably essential skill to detect the effect of external or internal stimuli on cell genesis. Immunohistochemical staining using Bromodeoxyuridine (BrdU), enables quantification of proliferative fraction of cells in sectioned tissues. BrdU, an artificial nucleoside that substitutes for thymidine. It is currently quite popular research tool of choice for new cell genesis studies. It incorporates into the DNA during S-phase of the cell cycle that's why used for birth dating and observing cell proliferation. BrdU immunohistochemistry is currently the most used technique for studying adult cell genesis in situ. In this article we provide a step-by step protocol for immunodetection of BrdU by light microscopy using avian species (loceus philippinus); starting from BrdU administration to the final analysis.
\end{abstract}

Keywords: Bromodeoxyuridine; cell proliferation; Immunohistochemistry; adult bird brain

Received: $16^{\text {th }}$ February 2020

Accepted: $23^{\text {rd }}$ March 2020

Published Online: $29^{\text {th }}$ March 2020
*Correspondence to: Yatinesh Kumari, Jeffrey Cheah School of Medicine and Health Sciences, Monash University Malaysia, Jalan Lagoon Selatan, Bandar Sunway, Subang Jaya, Selangor, 47500, Malaysia; yatinesh.kumari@ monash.edu

Citation: Kumari Y. Bromodeoxyuridine (BrdU) marker for proliferating cells in living tissues: Detection in adult avian brain. Prog Drug Discov Biomed Sci 2020; 3(1): a0000062. https://doi.org/10.3687/pddbs.a0000062

\section{Introduction}

Measuring the synthesis of new DNA is the most precise way for the measurement of cell proliferation in the living tissue. It can be utilized for birth-date proliferation measurement by furnishing exogenous markers that can amalgamated into the DNA of the cells ${ }^{[1]}$. The traditional approach for the detection of the cell proliferation was incorporation of [3H]-thymidine by using autoradiography. Because of radioactivity of $[3 \mathrm{H}]$-thymidine and the relatively long procedure for autoradiography, over the years other alternatives have been introduced. The most commonly used to date is 5-bromo-2'-deoxyuridine (BrdU).

BrdU (5'-bromo-2'-deoxyuridine) is a thymidine analog that has been established as a popular tool in the field of pathology and neuroscience research for determination of cell proliferation in a wide variety of species ${ }^{[2]}$. BrdU is characterized by a very similar chemical structure to thymidine. It has bromine Instead of 5-methyl group in thymidine ${ }^{[3]}$.
A. Cell cycle

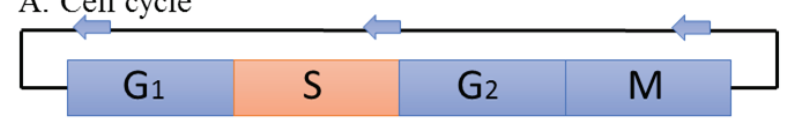

B. Exogenous replication markers

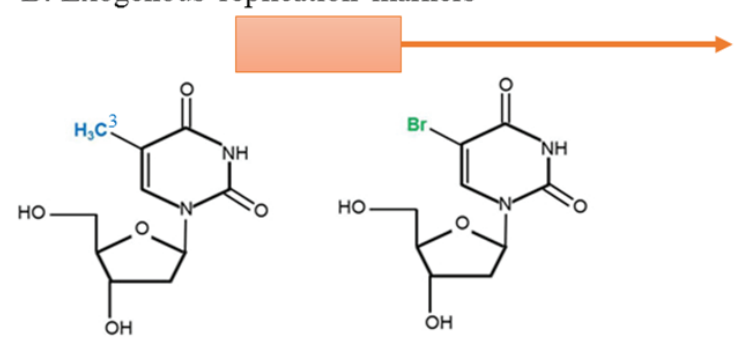

$[3 \mathrm{H}]$-thymidine

5-bromo-2'-deoxyuridine (BrdU)

Figure 1. Exogenous replication markers incorporation during S-phase of the cell cycle. A) Cell cycle; B) Chemical structure of exogenous replication markers

Several studies demonstrated that adult neurogenesis is a well-known feature throughout the animal kingdom. And in the avian telencephalon, brain cells genesis has been reported very well. Especially Passeriformes birds 
have remarkable capacity for brain cells regeneration in different seasons. This makes them an ideal model organism to study adult brain cell genesis. The proposed protocol in this article is subjected to use for other species as well.

In this article we are focusing on immunohistochemical staining using DAB (chromogen) for detection and visualization of BrdU antibody. There is an advantage of DAB chromogenic staining as it is not sensitive to light and insoluble in alcohol and xylene. So, it will not hinder the analysis and the slides can be stored for several years.

The important aspect of this stating procedure is BrdU administration. Commonly it is injected intraperitoneally, but it can also be given in drinking water or injected locally into the brain ventricles. Altogether, it takes 3-5 days, including, tissue harvesting, sectioning and staining.

\section{Materials and Methods}

\section{Animals}

The present study was carried out on adult male birds; Ploceus philippinus. The study was done in accordance with the guidelines of the Institutional Animal Ethics Committee (IAEC); Department of Zoology, University of Lucknow, Lucknow 226 007, India.

\section{BrdU Labelling}

There are several methods for BrdU labelling in-vivo. The most common mode of administration is intraperitoneal injection. Usually, BrdU tag cells for only about $2 \mathrm{hrs}$ after injection ${ }^{[4]}$. Number and age of the animals depend on the experimental requirement. Usually 5-8 animals per group is recommended in many studies ${ }^{[5,6]}$.

\section{Steps-}

1. Dilute the $\mathrm{BrdU}$ in $0.9 \% \mathrm{NaCl}(\mathrm{pH} 7.5-8.0)$ to make a sterile solution of $10 \mathrm{mg} / \mathrm{mL}$.

2. Administer the prepared BrdU solution to a concentration of $100 \mathrm{mg} / \mathrm{kg}^{[7]}$.

3. Good to have two consecutive identical doses, separated by 2 hours. A double BrdU dose is to minimize the error, if any, in the manual administration ${ }^{[8]}$.

4. After administration of BrdU, animal can be sacrificed according to the experimental desire.

\section{Tissue processing}

Processing tissue for immunohistochemistry is a very important and crucial step to prevent alteration in the results. The correct method helps to preserve the tissue and its cellular morphology. There are several methods for tissue processing such as paraffin-embedding, and frozen tissue processing. Here we discuss about frozen tissue processing.

\section{Steps}

1. Fix the brain samples as soon as possible after collection by using $4 \%$ paraformaldehyde $(\mathrm{pH} \sim 7.4)$. Keep Samples in same solution for overnight (10$12 \mathrm{hrs}$ ) at $4^{\circ} \mathrm{C}$ for the proper fixation.

2. Then transfer the brain samples in $10 \%$ Sucrose solution at $4^{\circ} \mathrm{C}$ (up to 5-6 hours).

3. Later, $10 \%$ sucrose solution can replace with $20 \%$ sucrose solution (overnight) and finally with 30\% sucrose solution at $4{ }^{\circ} \mathrm{C}$ until brain sinks to the bottom of the tube ${ }^{[9]}$ (Ekström et al., 2001).

4. Sectioning can be done by using cryostate [Ideal thickness for brain tissue is $40 \mu \mathrm{m}$; if collected in wells (24 well plate) filled with phosphate buffered saline (PBS; $10 \mathrm{~mm}, \mathrm{pH} 7.4)^{[10]}$.

5. Section samples can be stored at $-20^{\circ} \mathrm{C}$ in cryoprotectant until further uses for IHC.

\section{BrdU immunohistochemistry}

There are few methods for the detection of BrdU such as DAB method (analysis by using light microscopy), florescence methods (analysis by using florescence or confocal microscopy) etc. Here we are focusing on DAB method.

It is a two-days procedure for the detection of BrdU by using DAB method in avian brain. In order to make incorporated BrdU accessible to the antibodies, DNA hydrolysis (mild denaturation of the DNA) is important.

\section{Steps}

1. Incubate sections in $50 \%$ formamide $/ 2 \mathrm{XSSC}$ at $65^{\circ} \mathrm{C}$ for 2 hours to lower DNA temperature.

2. Wash the sections thoroughly for three times in $0.1 \mathrm{M}$ PBS with an interval of $5 \mathrm{~min}$.

3. Then incubated them in $2 \mathrm{~N} \mathrm{HCl}$ at $37^{\circ} \mathrm{C}$ for $30 \mathrm{~min}$ for denaturation of DNA.

4. Wash the sections for one time in a solution of $0.1 \mathrm{M}$ boric acid ( $\mathrm{pH} \mathrm{8.5)} \mathrm{for} 10 \mathrm{~min}$.

5. Again wash the section thoroughly for three times in $0.1 \mathrm{M}$ PBS with an interval of $5 \mathrm{~min}$.

6. After that incubated them in $3 \%-\mathrm{H}_{2} \mathrm{O}_{2}$ at room temperature to eliminate endogenous peroxidases for 30 $\min$.

7. Again wash the section thoroughly for three times in $0.1 \mathrm{M}$ PBS with an interval of $5 \mathrm{~min}$.

8. After that incubated them in blocking solution $(10 \%$ normal horse serum (Gibco, Thermo Fisher Scientific, USA) containing $0.1 \%$ Triton-X-100) at room temperature for 1 hour $30 \mathrm{~min}$ to eliminate non-specific binding of antibodies to tissue.

9. Then incubated the sections in anti-BrdU primary antibody (example- mouse anti-BrdU antibody; 1:500; Roche Diagnostics) prepared with combining 10\% horse serum, $0.5 \%$ bovine serum albumin (BSA) and $0.1 \%$ Triton-X-100 at $4{ }^{\circ} \mathrm{C}$ for overnight.

\section{Day two}

1. Wash the sections thoroughly for three times in $0.1 \mathrm{M}$ 
PBS with an interval of $5 \mathrm{~min}$.

2. Incubate them with the biotinylated secondary antibody (example- horse anti-mouse; 1:250; BA-2001, Vector Laboratories) prepared with combining $0.1 \%$ Triton-X-100 and $0.1 \mathrm{M}$ PBS at room temperature for 2 hours.

3. After incubation, wash the section thoroughly for three times in $0.1 \mathrm{M}$ PBS with an interval of $5 \mathrm{~min}$.

4. Incubate the sections with avidin-biotin complex (example- 1:55; Vectastain ABC Kit, Vector Laboratories) at the room temperature for 2 hours.

5. Again wash the sections thoroughly for three times in $0.1 \mathrm{M}$ PBS with an interval of $5 \mathrm{~min}$.

6. Incubate the sections at room temperature in diaminobenzidine solution (DAB, D4293; Sigma) prepared in $0.1 \mathrm{M}$ phosphate buffer ( $\mathrm{pH} 7.4$ ) for developing the color. Monitor DAB reaction on microscope for $2-10$ $\min$.

7. Once color developed, stop the reaction by immediately adding $0.1 \mathrm{M}$ PBS.

8. Finally, rinse them by using $0.1 \mathrm{M}$ PBS followed by water for two times each respectively with an interval of $5 \mathrm{~min}$.

9. These sections can be kept at $4^{\circ} \mathrm{C}$ for couple of days until mounting on the slides.

10. All the slides must be air dried under fume hood before the permanent slide preparation.

\section{Note}

Appropriate controls should be carried out for immunohistochemistry, consider including the following:

A known positive sample (BrdU injected-mouse brain sample)

Negative control (Saline; vehicle injection)

Unstained tissue (omission of primary antibody; mouse anti-BrdU)

Permanent preparation for the slides - To keep the sections safe for long, there is need to make permanent preparation.

\section{Steps}

1. Dehydrate the tissue using ethanol and xylene in the following sequence-
a. $70 \%$ Ethanol for $5 \mathrm{~min}$
b. $90 \%$ Ethanol for $5 \mathrm{~min}$
c. $100 \%$ Ethanol (1) for $5 \mathrm{~min}$
d. $100 \%$ Ethanol (2) for $5 \mathrm{~min}$
e. Xylene (1) for $10 \mathrm{~min}$
f. Xylene (2) for $10 \mathrm{~min}$
g. Xylene (3) for $10 \mathrm{~min}$

2. Cover the slides with glass coverslips using appropriate mounting media (example- DPX).

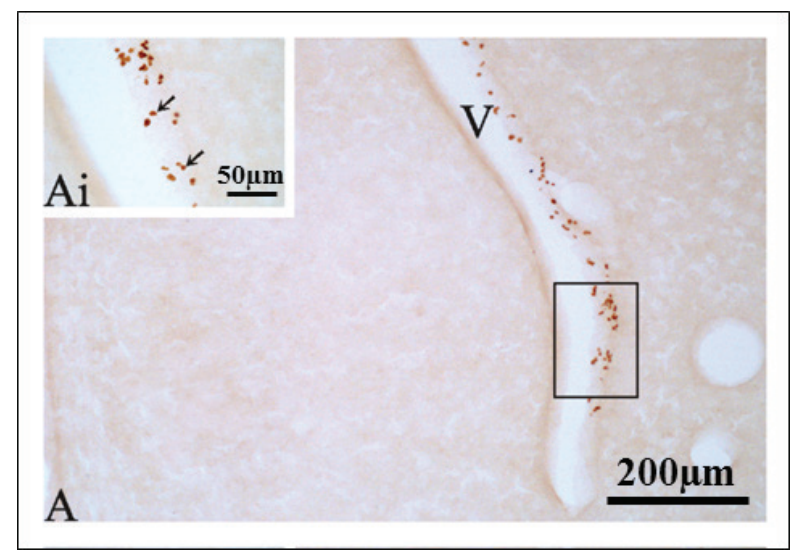

Figure 2. Images showing (A) BrdU positive cells (10X) in the region of lateral ventricle (V) of adult bird brain; (Ai) Magnified view (40X) under light microscope using DAB staining method.

\section{Quantitation of BrdU labeling (Analysis)}

There are many validated software's are available for the counting of BrdU labeling Such as NIS-Elements, Olympus, Cellsens and Leica Microscope Imaging Software etc. In most of the cases, researches use manual counting together with automated counting for the confirmation of the data. Here we are discussing manual counting of BrdU labeling which is a standard method to obtain validated data.

\section{Steps}

1. For quantification of BrdU labeling, all the brain sections must be analysed on same magnification (10X or 20X) by using fixed area frame for each section of interest.

2. To distinguish single cells within clusters, all counts must be performed at higher magnification (40X).

3. While quantification of BrdU labeled cells, experimenter must be blinded to the study code.

4. Two independent researchers do perform analysis (counting) as mentioned above to obtain validated data. 


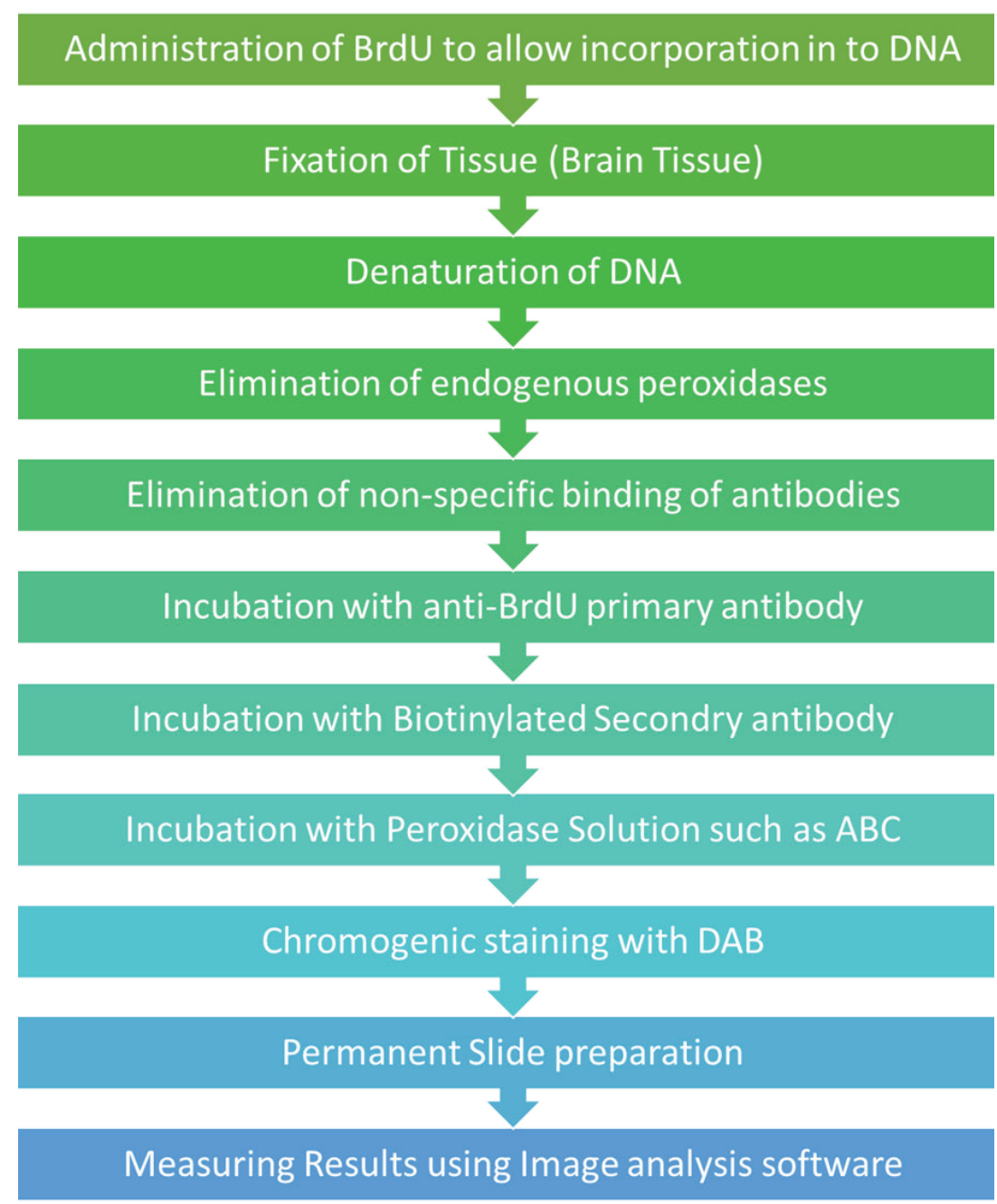

Figure 3. Flow chart of step-by step protocol for immunodetection of BrdU.

\section{Conclusion}

The BrdU staining procedure is a simple, rapid and sensitive method to detect the cell genesis. In summary, this established protocol could serve a useful guide for future endeavours such as detection of inhibitory or stimulatory effects of various compounds on brain cell genesis, quantification of brain cell genesis induced by cytokines, growth factors, and nutrients. It is also valuable to those who are new to the field of immunohistochemistry.

\section{Acknowledgements}

This work was supported by Department of Biological Sciences, Tata Institute of Fundamental Research, Homi Bhabha Road, Colaba, Mumbai 400 005, India

\section{Conflict of interest}

The authors declares that there is no conflict of interest in this work.

\section{Reference}

1. Takahashi T, Nowakowski RS, and Caviness VS. BUdR as an S-phase marker for quantitative studies of cytokinetic behaviour in the murine cerebral ventricular zone. J Neurocytol 1992; 21(3): 185-197.

2. Cecchini MJ, Amiri M, and Dick FA. Analysis of cell cycle position in mammalian cells. J Vis Exp 2012; 59: 3491.

3. Cattan A, Ayali A, Barnea A. The cell birth marker BrdU does not affect recruitment of subsequent cell divisions in the adult avian brain. BioMed Res Int 2015; 2015.

4. Cameron HA, and Mckay RD. Adult neurogenesis produces a large pool of new granule cells in the dentate gyrus. J Comp Neurol 2001; 435(4): 406-417.

5. Pozner T, Vistoropsky Y, Moaraf S, et al. Questioning seasonality of neuronal plasticity in the adult avian brain. Sci Rep 2018; 8(1): 11289.

6. Robertson BA, Rathbone L, Cirillo G, et al. Food restriction reduces neurogenesis in the avian hippocampal formation. PloS One 2017; 12(12)

7. Mao, Y., Ge, X., Frank, C.L., et al. Disrupted in schizophrenia 1 regulates neuronalprogenitor proliferation via modulation of GSK3 $\beta / \beta$-catenin signaling. Cell 2019; 136(6): 1017-1031

8. Lavenex P, Steele MA, and Jacobs LF. The seasonal pattern of cell proliferation and neuron number in the dentate gyrus of wild adult eastern grey squirrels. Eur J Neurosci 2000; 12(2): 643-648.

9. Ekström P, Johnsson CM, Ohlin LM. Ventricular proliferation zones in the brain of an adult teleost fish and their relation to neuromeres and migration (secondary matrix) zones. Journal of Comparative Neurology. 2001 Jul 17;436(1):92110 .

10. Yanpallewar SU, Fernandes K, Marathe SV, et al. $\alpha 2$ adrenoceptor blockade accelerates the neurogenic, neurotrophic, and behavioral effects of chronic antidepressant treatment. J Neurosci 2010; 30(3): 1096-1109. 